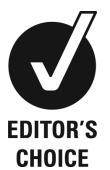

CHOICE

CASE REPORT

\title{
Alcohol use disorder due to social isolation after a nuclear disaster in Fukushima
}

\author{
Tomohiro Morita, ${ }^{1}$ Tetsuya Tanimoto, ${ }^{2}$ Arinobu Hori, ${ }^{3}$ Yukio Kanazawa ${ }^{4}$
}

${ }^{1}$ Soma Central Hospital, Soma, Fukushima, Japan

${ }^{2}$ Jyoban Hospital of Tokiwa-kai Group, Iwaki, Fukushima, Japan

${ }^{3}$ Hibarigaoka Hospital, Minamisoma, Fukushima, Japan

${ }^{4}$ Minamisoma Municipal General Hospital, Minamisoma, Fukushima, Japan

\section{Correspondence to} Dr Tomohiro Morita, t.morita526@gmail.com

Accepted 20 April 2015

\section{CrossMark}

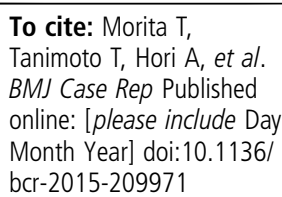

\section{SUMMARY}

It is well-known that a nuclear disaster causes health problems including cancer, however, information on mental disorders linked to a nuclear disaster is limited. On 11 March 2011, there was a serious nuclear power plant accident in Fukushima, Japan. Subsequently, in October 2012, a 78-year-old man living $31 \mathrm{~km}$ from the plant was admitted to the hospital with head trauma. This was his third physical trauma since the nuclear accident. A thorough interview revealed that his alcohol intake had increased after the disaster, suggesting that his injuries might be related to alcohol use. The diagnosis of alcohol use disorder was established based on the fifth edition of the Diagnostic and Statistical Manual of Mental Disorders. He had been exposed to social isolation after evacuation of his neighbourhood. Using education and intervention, he was successfully treated. We should recognise that a nuclear disaster might cause social isolation among the elderly, leading to mental disorders and alcohol use disorder. Early diagnosis and intervention might be beneficial for individuals presenting the above symptoms.

\section{CASE PRESENTATION}

In the last few decades, the construction of nuclear power plants has increased around the world, ${ }^{1}$ resulting in greater risk of nuclear accidents owing to human errors, natural disasters or terrorist attacks. A nuclear disaster can cause various health problems including leukaemia ${ }^{2}$ and thyroid cancer ${ }^{3}$ among children. A recent study suggests that a nuclear disaster might worsen chronic diseases such as diabetes mellitus or hyperlipidaemia as a result of adopting an inactive, indoor lifestyle in an attempt to reduce outdoor radiation exposures. ${ }^{4}$ In addition, it may cause mental problems such as post-traumatic stress disorder in addition to physical problems. ${ }^{5}$ However, information on the longterm impact of a nuclear disaster on mental status is limited. ${ }^{6}$

On 11 March 2011, eastern Japan was struck by multiple disasters comprising of an earthquake and a tsunami, followed by a nuclear power plant accident. Widespread radioactive contamination caused by the nuclear disaster affected the local community of Minamisoma City in Fukushima in particular, as it is located $10-30 \mathrm{~km}$ north of the damaged nuclear power plants. ${ }^{8}$ The government of Japan ordered mandatory evacuation in the area within $20 \mathrm{~km}$ radius of the plant. This was done as a precaution against health problems for evacuees. ${ }^{9}$ In contrast, support was relatively limited to those residents who lived outside of the evacuation area, and there is little information on their subsequent health problems. We report a case of an elderly man who lived outside of the evacuation area, whose alcohol use disorder was exacerbated after the accident.

In October 2012, a 78-year-old man with a history of hypertension and dyslipidemia, and living in Minamisoma City, presented with head trauma to our hospital. The patient had lost his wife 5 years earlier and lived with his 53-year-old daughter. Prior to the disaster, he visited our hospital regularly for the treatment of hypertension. Otherwise, he was in good health. He played pachinko (a Japanese arcade game) regularly, and gateball (Japanese croquet) after retirement. $\mathrm{He}$ consumed 15 standard alcohol drinks per week.

On 11 March 2011, he remained at his house, located $31 \mathrm{~km}$ from the nuclear power plants. His house was not damaged by the earthquake or the tsunami. He and his daughter survived the disaster without any injuries. However, after the disaster, his neighbours were evacuated for fear of radiation exposure without sufficient instructions of evacuation from the government. The patient subsequently stopped playing pachinko and gateball, stayed indoors, and suspended his follow-up appointments at our clinic.

On the current presentation for physical trauma, the patient smelled of alcohol and his speech was slurred, but he was neurologically intact. A 12-lead ECG was normal at the time of admission. A noncontrast CT of the head failed to show signs of intracranial haemorrhage or skull fractures. Medical history revealed that this was his third physical trauma in the past year; the previous two consisted of a head trauma in January 2012, and trauma of the left dorsal surface of the hand requiring sutures in May 2012, both of which were treated in the emergency department of the hospital. It was suspected that these unintentional injuries resulted from excessive alcohol use.

Additional history taking revealed that the patient was exposed to social isolation after he quit his social activities. He felt despair in the aftermath of the disaster, and his drinking increased from 15 to more than 30 standard alcohol drinks per week. $\mathrm{He}$ denied feeling depressed or having a loss of appetite, weight loss or any other symptoms of depression.

He was diagnosed with alcohol use disorder (indicated by a strong desire to use alcohol, excessive time spent intoxicated and continued use of alcohol despite problems) according to the fifth edition of the Diagnostic and Statistical Manual of Mental Disorders (DSM-V) by the American Psychiatric Association. ${ }^{10}$ 
After having identified his problems, he and his daughter were informed that his alcohol use disorder was related to social isolation and he was provided information on education programmes. In addition, we recommended him for regular visits to the clinic for follow-up on his alcohol use disorder.

As of January 2015, he has been visiting the hospital once a month and his drinking has decreased to the level before the disaster. He has not suffered any injury since his discharge.

\section{GLOBAL HEALTH PROBLEM LIST}

- Mental disorders after a nuclear disaster

- Social isolation among elderly residents

- Mental disorders outside of evacuation areas

\section{GLOBAL HEALTH PROBLEM ANALYSIS}

This case is of an elderly patient who developed alcohol use disorder, living outside of evacuation areas after the Fukushima nuclear disaster. Fast intervention ameliorated his symptoms promptly. This case provides three lessons.

First, we should pay more attention to the possibility of mental disorders after a nuclear disaster. A study revealed that mothers with young children were vulnerable to anxiety after a nuclear disaster. ${ }^{7}$ However, our case suggested that elderly residents might be vulnerable to mental disorders due to social isolation. Our patient experienced an exacerbation of alcohol use disorder. Interestingly, he was exposed to social isolation after the disaster, which is a risk factor for alcohol use disorder. ${ }^{11}$ As shown in this case, elderly residents are vulnerable to social isolation due to mass evacuation among young residents after a nuclear disaster. ${ }^{12}$ Thus, it is reasonable to assume that a nuclear disaster may cause alcohol use disorder especially among elderly people.

Second, a rapid-onset mental disorder caused by a sudden environmental change might be resolved rapidly with early intervention. Patients with alcohol use disorder will usually experience a chronic or recurring condition after psychosocial treatment. ${ }^{13}$ In contrast, alcohol use disorder of our patient was resolved after only a brief intervention. Early detection and intervention for patients with a rapid-onset mental disorder might contribute to minimising the mental impact of a nuclear disaster. In addition, up to three-quarters of patients have a relapse in the year after alcohol use treatment. We clinicians should inquire at regular follow-up visits about patients' alcohol consumption or related health problems to prevent the relapse of alcohol use disorder. ${ }^{14}$

Finally, mental disorders after a nuclear disaster may occur even outside of evacuation areas. Social support was provided for evacuees inside of evacuation areas. However, this case indicates that social support outside of evacuation areas was overlooked. It should be noted that the fear of radiation exposure was not diminished by being a farther distance from the nuclear plant or being exposed to a lower dose of radiation exposure. This corresponds with a report of the Chernobyl disaster, which revealed that the mental impact on adolescents was considerable even in an area of low ambient radiation exposure. This was due to limited information on the realistic uncertainty about the health consequences of radiation exposure. ${ }^{15}$
The Fukushima nuclear disaster has brought a decades long calamity to Japan. Sharing this experience would be useful for the global community in the event of a future nuclear accident. Physicians should also provide support for elderly residents living outside of evacuation areas to minimise casualties of a nuclear disaster.

\section{Learning points}

A nuclear disaster can cause alcohol use disorder especially among affected residents.

- A rapid-onset mental disorder caused by a sudden environmental change might be rapidly resolved with early intervention.

- Residents outside of the evacuation areas may still suffer from radiation exposure, as well as other health problems, due to social isolation after a nuclear disaster.

Competing interests None declared.

Patient consent Obtained.

Provenance and peer review Not commissioned; externally peer reviewed.

\section{REFERENCES}

1 Christoudias T, Proestos Y, Lelieveld J. Global risk from the atmospheric dispersion of radionuclides by nuclear power plant accidents in the coming decades. Atmos Chem Phys 2014;14:4607-16.

2 Preston DL, Kusumi S, Tomonaga $\mathrm{M}$, et al. Cancer incidence in atomic bomb survivors. Part III. Leukemia, lymphoma and multiple myeloma, 1950-1987. Radiat Res 1994;137(2 Suppl):S68-97.

3 Baverstock K, Egloff B, Pinchera A, et al. Thyroid cancer after Chernobyl. Nature 1992;359:21-2

4 Tsubokura $\mathrm{M}$, Kato $\mathrm{S}$, Nihei $\mathrm{M}$, et al. Limited internal radiation exposure associated with resettlements to a radiation-contaminated homeland after the Fukushima Daiichi nuclear disaster. PLOS ONE 2013;8:e81909.

5 Bromet EJ, Havenaar JM, Guey LT. A 25 year retrospective review of the psychological consequences of the Chernobyl accident. Clin Oncol 2011;23:297-305.

6 Gouweloos J, Duckers M, te Brake $\mathrm{H}$, et al. Psychosocial care to affected citizens and communities in case of CBRN incidents: a systematic review. Environ Int 2014; 72:46-65

7 Tarabrina N, Lazebnaya E, Zelenova M, et al. Chernobyl clean-up workers' perception of radiation threat. Radiat Prot Dosimetry 1996;68:251-5.

8 Nomura S, Gilmour S, Tsubokura M, et al. Mortality risk amongst nursing home residents evacuated after the Fukushima nuclear accident: a retrospective cohort study. PLOS ONE 2013;8:e60192.

9 Johnson C. Strategic planning for post-disaster temporary housing. Disasters 2007;31:435-58.

10 American Psychiatric Association. The Diagnostic and Statistical Manual of Mental Disorders: DSM 5. bookpointUS, 2013.

11 Ishikawa K, Kanazawa Y, Morimoto S, et al. Depopulation with rapid aging in Minamisoma City after the Fukushima Daiichi nuclear power plant accident. J Am Geriatr Soc 2012:60:2357-8.

12 Cutter S, Barnes K. Evacuation behavior and Three Mile Island. Disasters 1982:6:116-24

13 McLellan AT, Lewis DC, O'Brien CP, et al. Drug dependence, a chronic medical illness: implications for treatment, insurance, and outcomes evaluation. JAMA 2000;284:1689-95.

14 Friedmann PD. Alcohol use in adults. N Engl J Med 2013;368:365-73.

15 Koscheyev VS, Leon GR, Gourine AV, et al. The psychosocial aftermath of the Chernobyl disaster in an area of relatively low contamination. Prehosp Disaster Med 1997:12:41-6. 
Copyright 2015 BMJ Publishing Group. All rights reserved. For permission to reuse any of this content visit http://group.bmj.com/group/rights-licensing/permissions.

BMJ Case Report Fellows may re-use this article for personal use and teaching without any further permission.

Become a Fellow of BMJ Case Reports today and you can:

- Submit as many cases as you like

- Enjoy fast sympathetic peer review and rapid publication of accepted articles

- Access all the published articles

- Re-use any of the published material for personal use and teaching without further permission

For information on Institutional Fellowships contact consortiasales@bmjgroup.com

Visit casereports.bmj.com for more articles like this and to become a Fellow 